\title{
PROCESSAMENTO E AVALIAÇÃO DE ESTABILIDADE DE BEBIDA ISOTÔNICA EM GARRAFA PLÁSTICA
}

\author{
Rodrigo Rodrigues PETRUS', José de Assis Fonseca FARIA
}

\section{RESUMO}

Processou-se uma mistura isotônica com pH 3,4; objetivando-se a produção de uma bebida microbiologicamente estável, prescindindo de refrigeração. A bebida isotônica foi pasteurizada a $85^{\circ} \mathrm{C} / 5 \mathrm{~s} \mathrm{em}$ trocador de calor a placas e acondicionada em garrafas de polietileno tereftalato (PET) sanificadas por aspersão com solução de ácido peracético $0,3 \%$ durante $5 \mathrm{~s}$, a $30^{\circ} \mathrm{C}$. Foram processados 1 lote com $50 \mathrm{mg} / \mathrm{L}$ de sorbato de potássio, 1 lote com $100 \mathrm{mg} / \mathrm{L}$ e 1 lote sem sorbato. Os 3 lotes foram mantidos a $25^{\circ} \mathrm{C}$ durante 26 semanas, sendo realizadas determinações de $\mathrm{pH}$, sólidos solúveis, acidez total titulável, ácido ascórbico, testes de aceitação sensorial e contagens de microrganismos mesófilos aeróbios totais, bolores e leveduras durante a estocagem. Verificou-se diferença significativa $(p<0,05)$ entre as médias das determinações de ácido ascórbico, no início e fim do periodo de estocagem, para os três lotes processados. As contagens de bolores e leveduras e mesófilos aeróbios totais foram $<10 \mathrm{UFC} / \mathrm{mL}$ e $\leq 5,7 \mathrm{UFC} / \mathrm{mL}, \mathrm{res}-$ pectivamente, para os três lotes analisados durante as 26 semanas. As médias das notas atribuídas nos testes de aceitação sensorial não diferiram entre si $(\mathrm{p}<0,05)$ ao longo da estocagem. Os resultados obtidos evidenciaram a possibilidade de produção de uma bebida isotônica em garrafa de PET sem adição de conservadores químicos; visto que, o lote processado sem sorbato apresentou resultados microbiológicos confiáveis, aliados a sua satisfatória aceitação sensorial e estabilidade físico-química.

Palavras-chave: bebida isotônica; estabilidade; garrafa plástica.

\section{SUMMARY}

PROCESSING AND STABILITY EVALUATION OF ISOTONIC DRINK IN PLASTIC BOTTLE. The objective of this work was to obtain an isotonic drink by using pasteurization and packing into aseptic bottles, stable at room temperature, without the addition of chemical preservatives. For the sanitation of the plastic bottles some sanitizers were tested, based on their efficiency to destroy microorganism, maintaining minimum residual hydrogen peroxide, and keeping the drink sensory quality. The isotonic drink (pH 3,40 ) was thermaly processed in a plate pasteurizer at $85^{\circ} \mathrm{C} / 5 \mathrm{~s}$ and packed into PET bottles sanitized by spraying peracetic acid at $0.3 \% / 5 \mathrm{~s}$ at $30^{\circ} \mathrm{C}$. The processed drink contained three different concentrations of potassium sorbate (control, 50 and $100 \mathrm{mg} / \mathrm{L}$ ). The stability of the products were evaluated at $25^{\circ} \mathrm{C}$ for 26 weeks by measuring the pH, soluble solids, titrable acidity, ascorbic acid, microbial count, and sensory tests. The sensory evaluation and the count of the total mesophilic aerobic bacteria, moulds and yeast were measured during storage. There was no difference $(\mathrm{p}<0,05)$ for the $\mathrm{pH}$, soluble solids and acidity of the processed drinks during the storage period except for the ascorbic acid which reduced to about $30 \%$ of the initial value. At 26 weeks the total bacteria and mould and yeast count were $\leq 5.7 \mathrm{CFU} / \mathrm{mL}$ and $<10 \mathrm{CFU} / \mathrm{mL}$, respectively. There was no sensory evaluation diference $(\mathrm{p}<0,05)$ during the storage test. Such results indicated that the formulated isotonic drink can be processed at the above conditions, without the addition of chemical preservatives, and stored at room temperature for at least 6 months in good commercial quality.

Keywords: sport drink; stability; plastic bottle.

\section{1 - INTRODUÇÃO}

O consumo de bebidas esportivas, denominadas repositores hidroeletrolíticos ou isotônicos, tem experimentado um crescimento expressivo nos últimos anos. Classificados como alimentos para praticantes de atividades fisicas, esta categoria de bebidas é especialmente formulada para suprir as necessidades relacionadas aos exercícios físicos; ou seja, para facilitar a reidratação após ou durante a prática de exercícios intensos [13].

\section{1 - Definição e caracteristicas}

Uma bebida isotônica é aquela que apresenta concentração de substâncias ou minerais semelhantes às en-

Recebido para publicação em 03/08/2004. Aceito para publicação em 11/08/2005(001384).

Departamento de Engenharia de Alimentos/Faculdade de Zootecnia e Engenharia de Alimentos - USP.E-mail:petrus@fzea.usp.br

Departamento de Tecnologia de Alimentos/Faculdade de Engenharia de Alimentos UNICAMP. Caixa Postal 6121, CEP: 13083862, Campinas-SP-Brasil.E-mail:assis@fea.unicamp.br

A quem a correspondência deve ser enviada. contradas nos fluidos orgânicos. O balanço entre os eletrólitos (minerais) evita a desidratação durante a prática esportiva. Um isotônico deve possuir a mesma pressão osmótica que o sangue humano. Essa característica permite que a bebida seja rapidamente absorvida após o consumo [13]. Os eletrólitos estão envolvidos na maioria dos processos biológicos e os mais importantes são: sódio, cloreto, potássio, cálcio, magnésio e fósforo [14].

A isotonicidade ou osmolalidade da bebida, expressa em $\mathrm{mOsm} / \mathrm{L}$, depende de sua pressão osmótica e é calculada a partir da concentração molal de cada eletrólito [14]. Os diferentes valores de osmolalidade classificam as bebidas como [8]:

- Hipotônicas: < $290 \mathrm{mOsm} / \mathrm{L}$

- Isotônicas: 290 - $330 \mathrm{mOsm} / \mathrm{L}$

- Hipertônicas: > $330 \mathrm{mOsm} / \mathrm{L}$

O valor osmótico do plasma sangüíneo humano varia de 285 a $295 \mathrm{mOsm} / \mathrm{L}$ [11].

A fabricação de bebidas repositoras de fluidos é, primariamente, uma questão de mistura de ingredientes. $\mathrm{O}$ sabor básico dos eletrólitos presentes na bebida é pouco agradável e a adição de flavorizantes à base de frutas é uma prática usual. Tipicamente, isotônicos são bebidas 
não carbonatadas, de elevada acidez, com baixo conteúdo de carboidratos, variando de 6 a $8 \%$ [13].

A elevada acidez das bebidas isotônicas, com pH próximo a 3,5, favorece, principalmente, o desenvolvimento de bolores e leveduras; normalmente não oferecendo risco à saúde humana. Alterações sensoriais são detectadas, na maioria das vezes, quando contagens microbianas são superiores a $10^{\prime} \mathrm{UFC} / \mathrm{mL}$, atingindo o máximo em valores na faixa de 10 a $10 \mathrm{UFC} / \mathrm{mL}$ [6].

\section{2 - Alternativas de processamento e envase pa- ra isotônicos}

As bebidas isotônicas estão disponiveis na forma de pós, concentrados e prontas para beber. Nesse último caso, o produto pode ser termicamente tratado e envasado a temperatura ambiente, em condições assépticas ou quando um agente conservador é adicionado. Ainda existe a opção do enchimento a quente, utilizando-se garrafas de vidro ou PET termofixado, também conhecido como garrafas heat set [7]. A Figura 1 ilustra as alternativas tecnológicas dos processos de acondicionamento de bebidas isotônicas.

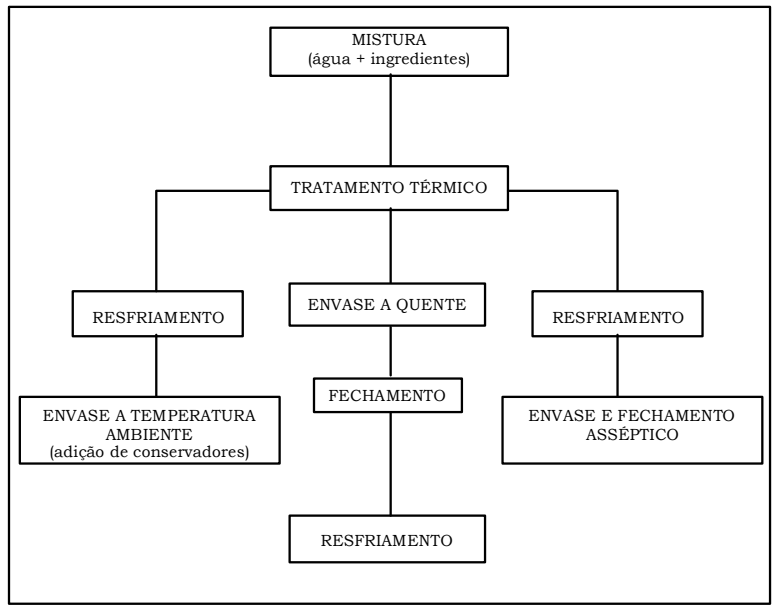

FIGURA 1 - Alternativas de processos e sistemas de envase para bebidas isotônicas [7]

As bebidas isotônicas podem ser acondicionadas em embalagens flexiveis auto-sustentáveis do tipo cheer pack, formadas a partir de filmes laminados compostos de 4 materiais diferentes: poliéster na parte externa, alumínio (barreira ao oxigênio), náilon (resistência) e polietileno no interior, no canudo e na tampa [4], em latas de aluminio, copos de polipropileno, laminados cartonados e garrafas de vidro e PET.

No atual estágio em que se encontram os sistemas de acondicionamento, que visam o aumento da estabilidade do produto nas prateleiras, redução do uso de conservadores e da necessidade de refrigeração, a assepsia, que é imperativa na indústria farmacêutica, vem sendo cada vez mais empregada no setor alimentício [1].

\section{3 - Conservação de isotônicos}

$\mathrm{Na}$ conservação das bebidas isotônicas podem ser considerados quatro obstáculos atuantes, isolada ou conjuntamente, que garantem a estabilidade e segurança microbiológica do produto:

- $\quad$ Alta acidez $(\mathrm{pH}<4,6)$;

- Tratamento térmico (pasteurização);

- Adição de conservadores químicos;

- Assepsia e adequação da embalagem.

Diante do exposto, esta pesquisa visou a elaboração e produção de uma bebida isotônica em garrafa plástica microbiologicamente estável, prescindindo de refrigeração.

\section{2 - MATERIAL E MÉTODOS}

\section{1 - Formulação isotônica}

A bebida isotônica foi preparada por dissolução dos ingredientes em água deionizada, cuja formulação, com teor de sólidos próximo a 7\%, é apresentada na Tabela 1. As concentrações do conservador químico (sorbato de potássio) adicionadas foram 50 e $100 \mathrm{mg} / \mathrm{L}$, e 1 lote sem conservador atuando como controle.

A formulação da mistura isotônica $(\mathrm{pH}=3,4)$, baseado em RUSIG [9], foi ajustada tendo como referência o valor osmótico do plasma sangüíneo humano, que varia de 285 a 295 mOsmolal [10].

TABELA 1 - Formulação isotônica utilizada [9]

\begin{tabular}{lc}
\hline \multicolumn{1}{c}{ INGREDIENTES } & COMPOSIÇÃO $(\mathrm{g} / \mathrm{L})$ \\
\hline Sacarose & 44,914 \\
Glucose anidra & 20,138 \\
Fosfato de potássio & 0,317 \\
Cloreto de sódio & 0,427 \\
Sorbato de potássio & $0-0,100$ \\
Citrato de sódio & 0,208 \\
Ácido cítrico & 0,638 \\
Ácido ascórbico & 0,120 \\
Aroma de laranja & 1,500 \\
\hline
\end{tabular}

\section{2 - Medida do valor osmótico da bebida isotô-} nica

O valor osmótico da bebida foi determinado através da metodologia de osmometria de pressão de vapor, em um osmômetro de pressão de vapor, Knauer modelo A0280, através da medida do número de partículas osmoticamente ativas.

\section{3 - Embalagem}

Foram utilizadas garrafas transparentes de PET de $500 \mathrm{~mL}$ e tampas de polipropileno. Tais embalagens apresentavam-se em uma unidade paletizada totalizando-se 2000 unidades das quais foram retiradas as amostras para a assepsia e acondicionamento da bebida. 


\section{4 - Sanificante químico}

O sanificante utilizado na assepsia das embalagens foi uma mistura contendo $0,3 \%$ de ácido peracético e 0,46\% de peróxido de hidrogênio.

\section{5 - Delineamento do tratamento térmico da be- bida isotônica}

O binômio tempo/temperatura delineado para o processamento da bebida foi baseado nas seguintes premissas:

- Foram considerados os limites superiores das faixas aproximadas de resistência térmica de bolores eleveduras para alimentos de alta acidez que, conforme VARNAM \& SUTHERLAND [12], são $\mathrm{D}_{\mathrm{s}, \mathrm{s}, \mathrm{c}}=0,5$ 1,0 min e $z=8-10^{\circ} \mathrm{C}$. Ou seja, foram assumidos os valores $\mathrm{D}_{\mathrm{c} s, \mathrm{c}, \mathrm{c}}=1,0$ minuto $\mathrm{e} z=10^{\circ} \mathrm{C}$;

- O número inicial de microrganismos na bebida $\left(\mathrm{N}_{0}\right) \mathrm{e}$ de sobreviventes após a pasteurização $(\mathrm{N})$ assumidos foram $10^{\circ}$ e $10^{\circ} \mathrm{UFC} / \mathrm{mL}$, respectivamente.

Aplicando as equações das curvas de destruição térmica $\mathrm{F}=(\log \mathrm{N}$ - $\log \mathrm{N}) \mathrm{D}$, onde $\mathrm{F}$ representa o tempo de aquecimento a uma dada temperatura, e de tempo de destruição térmica $\mathrm{D}_{1}=\mathrm{D}_{2} \cdot 10^{172 \cdot 71 / 2}$, alguns binômios, equivalentes, foram calculados: $65,6^{\circ} \mathrm{C} / 6 \mathrm{~min}, 78^{\circ} \mathrm{C} / 21 \mathrm{~s}$, $80^{\circ} \mathrm{C} / 13 \mathrm{~s}, 85^{\circ} \mathrm{C} / 5 \mathrm{~s}$.

As caracteristicas do trocador de calor utilizado e a busca por um tratamento térmico menos agressivo às qualidades nutricional e sensorial do produto justificaram a escolha da condição de tratamento igual a $85^{\circ} \mathrm{C} / 5 \mathrm{seg}$

\section{6 - Elaboração e processamento em escala pilo- to}

A elaboração, pasteurização da bebida e assepsia das embalagens foram conduzidos na planta piloto do Departamento de Tecnologia da Faculdade de Engenharia de Alimentos da UNICAMP, conforme o diagrama de fluxo representado pela Figura 2.

\section{7 - Preparação da bebida}

Os lotes da bebida isotônica foram preparados em batelada por dissolução dos ingredientes em água deionizada e agitação em um tanque de aço inoxidável com capacidade para 100L. Foram preparados três lotes de $80 \mathrm{~L}$, sendo um controle (sem sorbato), um com $50 \mathrm{mg} / \mathrm{L}$ de sorbato e um com 100mg/L. Depois de homogeneizado, o produto foi bombeado ao trocador de calor para pasteurização. Os lotes foram identificados da seguinte maneira:

- $\quad$ Lote 1 - 100mg/L de sorbato;

- $\quad$ Lote 2 - 50mg/L de sorbato;

- Lote 3 - controle.

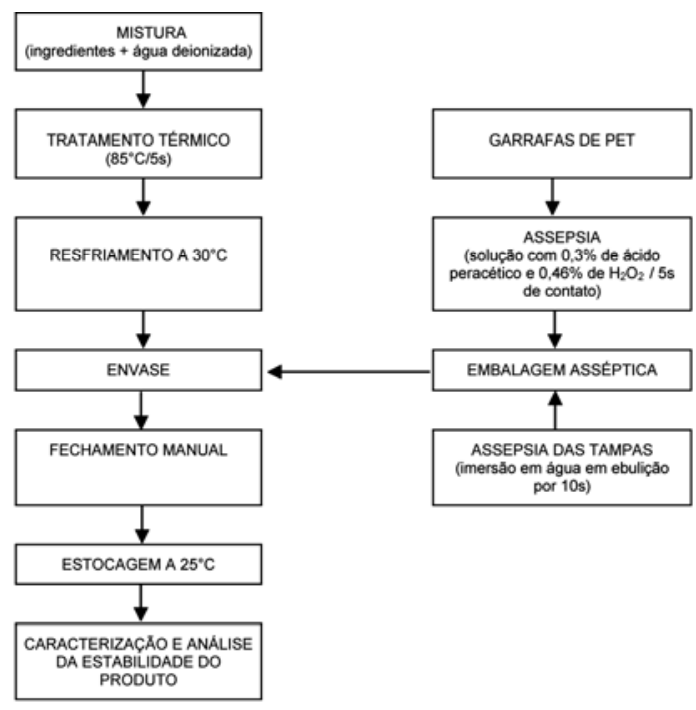

FIGURA 2 - Diagrama de fluxo de processamento e envase da bebida isotônica

\section{8 - Pasteurização}

A bebida isotônica foi pasteurizada em trocador de calor a placas a $85^{\circ} \mathrm{C} / 5 \mathrm{~s}$. O produto pasteurizado foi armazenado em um tanque de aço inoxidável fechado durante um tempo aproximado de 30 minutos e envasado em garrafas de PET de $500 \mathrm{~mL}$ sanificadas.

\section{9 - Assepsia das embalagens}

As embalagens foram sanificadas e enxagüadas por aspersão. Uma solução contendo 0,30\% de ácido peracético e $0,46 \%$ de $\mathrm{H}_{2} \mathrm{O}_{2}$ a $30^{\circ} \mathrm{C}$ foi aspergida no interior das garrafas durante 5 segundos. As tampas foram esterilizadas por imersão em água fervente durante 10 segundos. O enxágüe final das garrafas foi feito por aspersão de água a $50^{\circ} \mathrm{C}$ durante 7 segundos, filtrada e fervida.

\subsection{0 - Caracterização físico-química da bebida} isotônica

As seguintes análises físico-químicas dos 3 lotes produzidos, foram realizadas com 2, 16 e 26 semanas de estocagem a $25^{\circ} \mathrm{C}$ :

- $\quad$ Potencial de hidrogênio $(\mathrm{pH})$;

- Sólidos solúveis totais ( $\left.{ }^{\circ} \mathrm{Brix}\right)$, medido por refratometria;

- Acidez total titulável (ATT) determinada por titulação com solução de hidróxido de sódio $0,1 \mathrm{~N}$ padronizada;

- Ácido ascórbico, titulado com diclorofenolindofenol;

- Osmolalidade em osmômetro de pressão de vapor, realizada apenas durante o desenvolvimento da formulação isotônica. 


\subsection{1 - Avaliação da estabilidade microbiológica}

Os lotes da bebida produzidos foram mantidos a $25^{\circ} \mathrm{C}$, sendo três unidades de cada lote retiradas, para análises microbiológicas realizadas no dia seguinte ao processamento, com 2, 4, 8, 16 e 26 semanas de estocagem. Como indicadores da estabilidade do produto foram feitas contagens de microrganismos aeróbios mesófilos em profundidade e bolores e leveduras em superfície. Os limites que definiram a conformidade do produto, propostos por LEITÃO [6], foram:

- Contagem padrão: $\leq 10 \mathrm{UFC} / \mathrm{mL}$;

- Bolores eleveduras: $\leq 10 \mathrm{UFC} / \mathrm{mL}$.

\subsection{2 - Teste de aceitação sensorial}

Amostras do lote sem adição de conservador químico foram analisadas com 2, 16 e 26 semanas de estocagem a $25^{\circ} \mathrm{C}$, por um painel de 50 provadores não treinados, que avaliou o grau de aceitação do produto quanto à aparência e sabor. As amostras foram servidas aos provadores a uma temperatura média de $9^{\circ} \mathrm{C}$. Os testes foram realizados em cabines individuais iluminadas com luz branca utilizando-se uma escala hedônica verbal de nove pontos [2].

\section{3 - RESULTADOS E DISCUSSÃo}

\section{1 - Determinação do valor osmótico da mistu- ra isotônica}

A determinação da osmolalidade da mistura foi precedida pela construção de uma curva padrão, mostrada na Figura 3, utilizando soluções de cloreto de sódio $(\mathrm{NaCl})$.

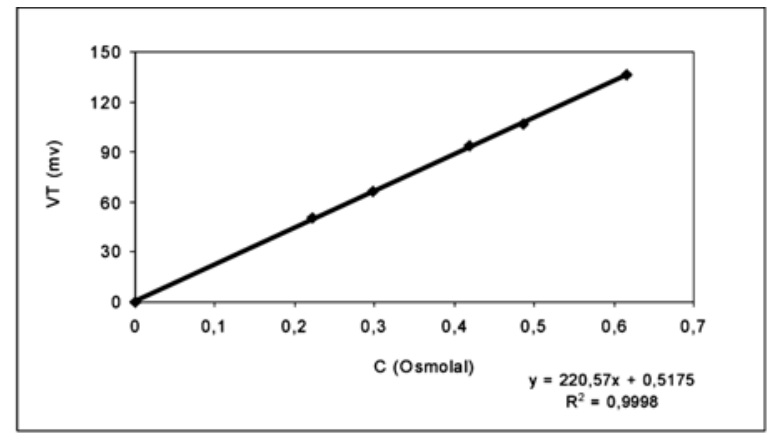

FIGURA 3 - Curva padrão para determinação do valor osmótico da bebida isotônica

Para a formulação mostrada na Tabela 1, a média das leituras do sinal elétrico (VT) detectado pelo osmômetro de pressão de vapor foi igual a $63,7 \mathrm{mV}$. Substituindo esse valor na equação de regressão da Figura 3, obteve-se 0,2865 Osmolal; valor esse dentro da faixa do valor osmótico do plasma sangüineo humano, que varia de 0,285 a 0,295 Osmolal, conforme SREBERNICH [11].

\section{2 - Análises físico-quimicas e microbiológicas da bebida isotônica pasteurizada}

\subsection{1 - Análises físico-químicas}

Os resultados, expressos como média das três amostras, estão apresentados nas Tabelas 2, 3, 4 e 5 . As médias dos resultados obtidos foram comparadas, separadamente para cada lote, para verificar a existência de diferença estatisticamente significativa entre as amostras analisadas nos três períodos de estocagem.

As determinações de $\mathrm{pH}$, sólidos solúveis, acidez total titulável e ácido ascórbico podem ser observadas nas Tabelas 2, 3, 4 e 5, respectivamente.

TABELA 2 - Resultados das determinações de pH para os três lotes de bebida isotônica pasteurizada

\begin{tabular}{ccccccc}
\hline \multirow{2}{*}{$\begin{array}{c}\text { ESTOCAGEM } \\
\text { (semanas) }\end{array}$} & \multicolumn{2}{c}{$\begin{array}{c}\text { LOTE } 1 \\
\text { (100 mg/L de sorbato) }\end{array}$} & \multicolumn{2}{c}{$\begin{array}{c}\text { LOTE } 2 \\
\text { (50 mg/Ll de sorbato) }\end{array}$} & \multicolumn{2}{c}{$\begin{array}{c}\text { LOTE } 3 \\
\text { (0 m/L de sorbato) }\end{array}$} \\
\cline { 2 - 7 } & média & $\mathrm{dp}$ & média & $\mathrm{dp}$ & média & $\mathrm{dp}$ \\
\hline 2 & $3,4^{\mathrm{a}}$ & 0,0 & $3,4^{\mathrm{a}}$ & 0,0 & $3,2^{\mathrm{a}}$ & 0,0 \\
16 & $3,5^{\mathrm{b}}$ & 0,0 & $3,5^{\mathrm{b}}$ & 0,0 & $3,4^{\mathrm{b}}$ & 0,0 \\
26 & $3,4^{\mathrm{a}}$ & 0,0 & $3,4^{\mathrm{a}}$ & 0,0 & $3,3^{\mathrm{a}, \mathrm{b}}$ & 0,0 \\
\hline médias com o mesmo expoente, na mesma coluna, năo såo significativamente diferentes (p<0,05).
\end{tabular}

TABELA 3 - Resultados das determinações de sólidos solúveis ( $\left.{ }^{\circ} \mathrm{Brix}\right)$ para os três lotes de bebida isotônica pasteurizada

\begin{tabular}{|c|c|c|c|c|c|c|}
\hline \multirow[t]{2}{*}{$\begin{array}{l}\text { ESTOCAGEM } \\
\text { (semanas) }\end{array}$} & \multicolumn{2}{|c|}{$\begin{array}{c}\text { LOTE } 1 \\
\text { (100 mg/L de sorbato }\end{array}$} & \multicolumn{2}{|c|}{$\begin{array}{c}\text { LOTE } 2 \\
(50 \mathrm{mg} / \mathrm{L} \text { de sorbato })\end{array}$} & \multicolumn{2}{|c|}{$\begin{array}{c}\text { LOTE } 3 \\
(0 \mathrm{mg} / \mathrm{L} \text { de sorbato }\end{array}$} \\
\hline & média & $\mathrm{dp}$ & média & $\mathrm{dp}$ & média & $\mathrm{dp}$ \\
\hline 2 & $6,2^{\star}$ & 0,3 & $6,3^{a}$ & 0,2 & $6,0^{a}$ & 0,1 \\
\hline 16 & $6,4^{\circ}$ & 0,2 & $6,8^{\mathrm{a}}$ & 0,3 & $6,4 \mathrm{a}$ & 0,2 \\
\hline 26 & $5,9 *$ & 0,3 & $6,5^{\mathrm{a}}$ & 0,3 & $6,1^{a}$ & 0,3 \\
\hline
\end{tabular}
dp - desvio padrăo.

TABELA 4 - Resultados das determinações de acidez total titulável (ATT) para os três lotes de bebida isotônica pasteurizada*

\begin{tabular}{|c|c|c|c|c|c|c|}
\hline \multirow[t]{2}{*}{$\begin{array}{l}\text { ESTOCAGEM } \\
\text { (semanas) }\end{array}$} & \multicolumn{2}{|c|}{$\begin{array}{c}\text { LOTE } 1 \\
(100 \mathrm{mg} / \mathrm{L} \text { de sorbato) }\end{array}$} & \multicolumn{2}{|c|}{$\begin{array}{c}\text { LOTE } 2 \\
(50 \mathrm{mg} / \mathrm{L} \text { de sorbato) }\end{array}$} & \multicolumn{2}{|c|}{$\begin{array}{c}\text { LOTE } 3 \\
(0 \mathrm{mg} / \mathrm{L} \text { de sorbato) }\end{array}$} \\
\hline & média & $\mathrm{dp}$ & média & dp & média & dp \\
\hline 2 & $0,1^{a}$ & 0,0 & $0,1^{a}$ & 0,0 & $0,1^{\mathrm{a}}$ & 0,0 \\
\hline 16 & $0,1^{a}$ & 0,0 & $0,1^{a}$ & 0,0 & $0,1^{a}$ & 0,0 \\
\hline 26 & $0,1^{a}$ & 0,0 & $0,1^{\circ}$ & 0,0 & $0,1^{\mathrm{a}}$ & 0,0 \\
\hline
\end{tabular}
dp - desvio padráo.

TABELA 5 - Resultados das determinações de ácido ascórbico para os três lotes de bebida isotônica pasteurizada*

\begin{tabular}{|c|c|c|c|c|c|c|}
\hline \multirow[t]{2}{*}{$\begin{array}{l}\text { ESTOCAGEM } \\
\text { (semanas) }\end{array}$} & \multicolumn{2}{|c|}{$\begin{array}{c}\text { LOTE } 1 \\
(100 \mathrm{mg} / \mathrm{L} \text { de sorbato })\end{array}$} & \multicolumn{2}{|c|}{$\begin{array}{c}\text { LOTE } 2 \\
(50 \mathrm{mg} / \mathrm{L} \text { de sorbato }\end{array}$} & \multicolumn{2}{|c|}{$\begin{array}{c}\text { LOTE } 3 \\
(0 \mathrm{mg} / \mathrm{L} \text { de sorbato })\end{array}$} \\
\hline & média & $\mathrm{dp}$ & média & $d p$ & média & $\mathrm{dp}$ \\
\hline 2 & 10,0 & 0,3 & $10,1^{*}$ & 0,2 & $10,1^{\mathrm{a}}$ & 0,2 \\
\hline 16 & $6,3^{3}$ & 1,0 & $6,3^{b}$ & 1,0 & $6,3^{\circ}$ & 1,0 \\
\hline 26 & $3,2 \circ$ & 0,0 & 2,9 & 0,5 & 3,2 & 0,8 \\
\hline
\end{tabular}

Dentre as alterações físico-químicas avaliadas, a que apresentou maior intensidade foi a redução de vitamina $\mathrm{C}$, atingindo $17 \%(12 \Rightarrow 10 \mathrm{mg} / 100 \mathrm{~mL})$ durante a pasteurização e $70,7 \%(10 \Rightarrow 2,93 \mathrm{mg} / 100 \mathrm{~mL})$, considerando o lote 2 , durante 26 semanas de estocagem a $25^{\circ} \mathrm{C}$, totalizando uma redução próxima a $76 \%$, em relação a 
quantidade inicial $(12 \mathrm{mg} / 100 \mathrm{~mL})$ adicionada durante a elaboração da bebida.

De acordo com FARIA [5], o ácido ascórbico é um forte agente redutor, cuja principal perda ocorre por degradação química, que, por sua vez depende da concentração de sal e açúcar, atividade de água, pH, concentração de oxigênio e temperatura. Se o índice de qualidade considerado na vida-de-prateleira do produto for degradação de vitamina, $50 \%$ de perda nutricional é bem comum na maioria dos casos reais.

A vida-de-prateleira da bebida isotônica poderia ser estabelecida, eventualmente, em função da degradação de vitamina $\mathrm{C}$, que após 16 semanas, atingiu 50\% de redução em relação ao valor inicial adicionado, conforme a Tabela 5. Entretanto, como uma bebida isotônica não tem, primariamente, a função de atuar como fonte de vitamina C, e sim como repositor hidroeletrolítico, essa perda não consistiria em fator crítico ou limitante da vidade-prateleira do produto.

\subsection{2 - Avaliação da estabilidade microbiológica}

- Contagem de microrganismos mesófilos aeróbios totais

As médias das contagens de microrganismos mesófilos aeróbios totais em três embalagens do lote 1 (100mg/L de sorbato), lote 2 (50mg/L de sorbato) elote $3(0 \mathrm{mg} / \mathrm{L}$ de sorbato) foram inferiores a 6,2 e $2 \mathrm{UFC} / \mathrm{mL}$, respectivamente, durante o período de 26 semanas de estocagem a $25^{\circ} \mathrm{C}$. Considerou-se, portanto, que as contagens para os três lotes, praticamente, não diferiram entre si e que a adição de conservador não interferiu na estabilidade do produto, indicando a possibilidade de sua eliminação.

- Contagem de bolores e leveduras

As médias das contagens de bolores e leveduras fo- ram inferiores a $10 \mathrm{UFC} / \mathrm{mL}$ para os três lotes de bebida produzidos, mantendo-se estável durante 26 semanas de estocagem a $25^{\circ} \mathrm{C}$.

A distribuição de microrganismos em uma amostra de alimento, ou mesmo entre amostras de um mesmo lote de produção não é necessariamente uniforme. Os planos de amostragem devem considerar a possivel distribuição de microrganismos dentro do lote, fator especialmente critico quando os niveis iniciais são inferiores a $10 \mathrm{UFC} / \mathrm{g}$ ou $\mathrm{mL}$, que representa o limite de sensibilidade dos procedimentos de plaqueamento usados nas análises. Niveis inferiores podem ser detectados, mas com menores exatidão e precisão [3].

A estabilidade microbiológica da bebida isotônica produzida pôde ser atribuída à ausência de microrganismos nas amostras analisadas ou ao fato de que os microrganismos contaminantes não foram capazes de se desenvolver na formulação do produto em condições normais de estocagem, independente da presença de conservador químico no meio.

\subsection{3 - Aceitação sensorial}

As médias das notas atribuídas à aparência e sabor são apresentadas na Tabela 6. Para a aparência, a média calculada classificou a bebida entre "gostei regularmente" e "gostei muito" dentro da escala hedônica aplicada, para os três periodos avaliados. A média para o sabor

TABELA 6 - Médias das notas dos testes de aceitação para o lote 3 (sem conservador) estocado a $25^{\circ} \mathrm{C}$

\begin{tabular}{ccc}
\hline \multirow{2}{*}{$\begin{array}{c}\text { TEMPO DE ESTOCAGEM } \\
\text { (semanas) }\end{array}$} & \multicolumn{2}{c}{ ATRIBUTO AVALIADO } \\
\cline { 2 - 3 } & aparência & sabor \\
\hline 2 & $7,9^{\circ}$ & $7,1^{\mathrm{b}}$ \\
16 & $7,7^{\star}$ & $6,6^{\mathrm{b}}$ \\
26 & $7,8^{\mathrm{a}}$ & $6,4^{\mathrm{b}}$ \\
\hline médias com o mesmo expoente nåo såo significativamente diferentes (p<0,05).
\end{tabular}

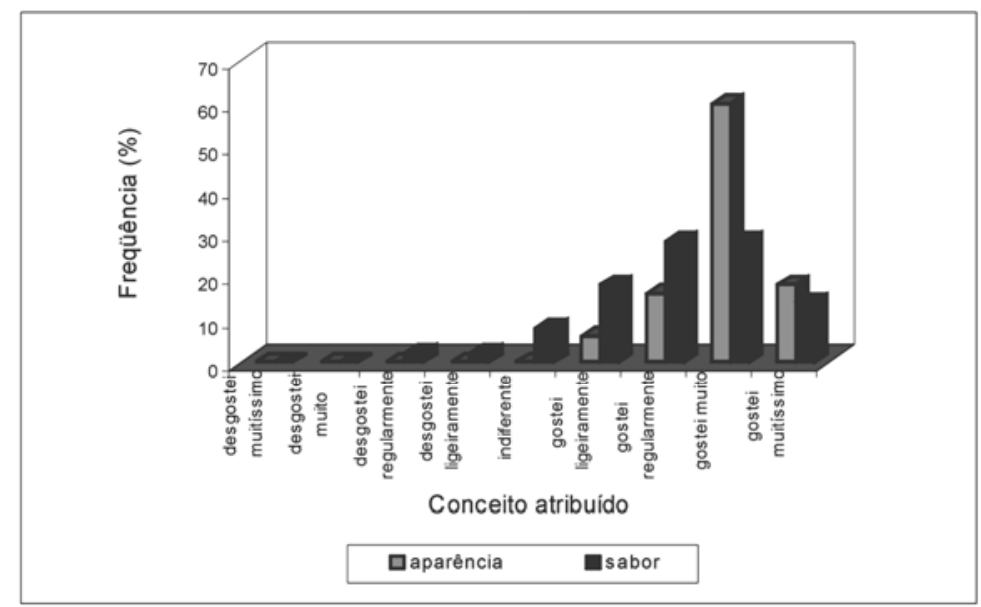

FIGURA 4 - Histograma do teste de aceitação para aparência e sabor do lote da bebida isotônica pasteurizada sem conservador químico com 2 semanas de estocagem a $25^{\circ} \mathrm{C}$ 


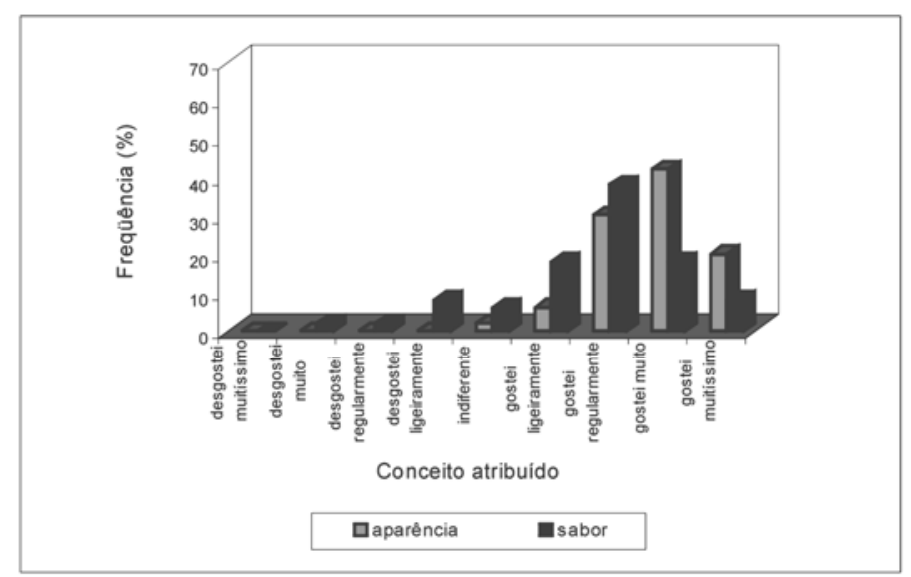

FIGURA 5 - Histograma do teste de aceitação para aparência e sabor do lote da bebida isotônica pasteurizada sem conservador químico com 16 semanas de estocagem a $25^{\circ} \mathrm{C}$

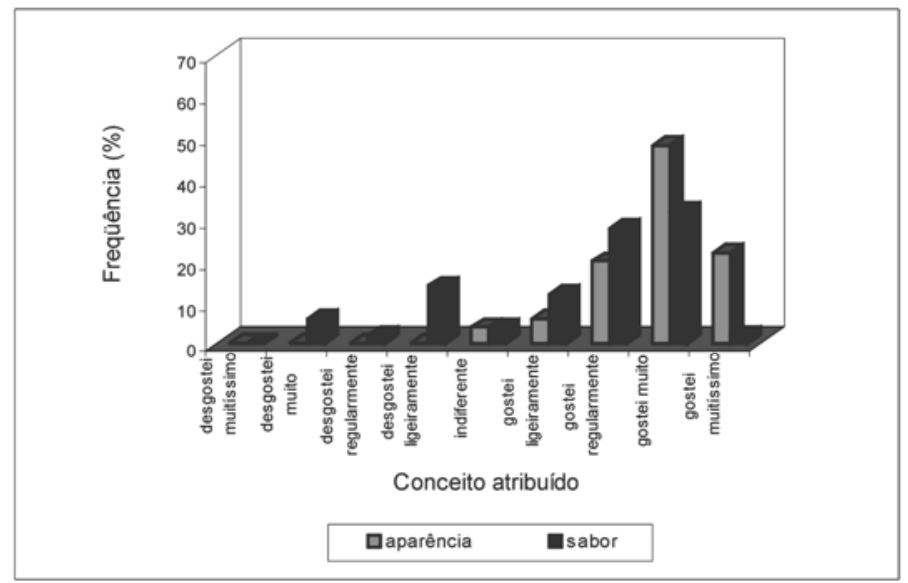

FIGURA 6 - Histograma do teste de aceitação para aparência e sabor do lote da bebida isotônica pasteurizada sem conservador químico com 26 semanas de estocagem a $25^{\circ} \mathrm{C}$

apresentou uma sensivel queda. No início, o produto foi classificado entre "gostei regularmente" e "gostei muito", e entre "gostei ligeiramente" e "gostei regularmente", com 16 e ao final de 26 semanas de estocagem.

A análise de variância (ANOVA) não apontou existência de diferença entre as amostras analisadas. O teste de Tukey indicou que as médias para ambos atributos avaliados não diferiram significativamente $(\mathrm{p}<0,05)$ entre $o$ início e fim do período de estocagem, demonstrando que o grau de aceitação sensorial da bebida se manteve durante 26 semanas.

As Figuras 4, 5 e 6 representam os histogramas dos testes de aceitação da bebida isotônica formulada sem adição de conservador, estocada a $25^{\circ} \mathrm{C}$ durante 2,16 e 26 semanas.

\section{4 - CONCLUSÕES}

- Os testes físico-químicos dos lotes da bebida isotônica indicaram, para o teor de ácido ascórbico, diferenças estatisticamente significativas $(p<0,05)$ entre as médias dos resultados obtidos no início e fim da estocagem.

- As análises microbiológicas da bebida isotônica pasteurizada e acondicionada em garrafas plásticas evidenciaram a estabilidade dos três lotes produzidos, indicando a possibilidade de eliminação do conservador químico da composição do produto.

- A bebida apresentou uma boa aceitação sensorial, quanto à aparência e sabor, não havendo variação estatisticamente significativa $(\mathrm{p}<0,05)$ entre as médias das notas atribuídas ao longo de 26 semanas de estocagem a $25^{\circ} \mathrm{C}$. 


\section{5 - REFERÊNCIAS BIBLIOGRÁFICAS}

[1] A ASSEPSIA NA EMBALAGEM. Embanews, São Paulo, v.8, n.4, p.24-26, abr., 1997.

[2] CHAVES, J. B. P; SPROESSER, R. L. Práticas de laboratório de análise sensorial de alimentos e bebidas. Viçosa: Imprensa Universitária, 1993. 81p.

[3] CURIALE, M. S. Shelf-life evaluation analysis. Dairy, Food and Environmental Sanitation, Des Moines, v. 11, n.7, p.364-369, July, 1991.

[4] EMBALAGEM: setor aposta em tecnologia. Plástico Moderno, São Paulo, n.289, p.65, jul., 1998.

[5] FARIA, J. A. F. Estabilidade de Alimentos em Embalagens Plásticas. Apostila de aula, Campinas, UNICAMP/FEA, 1990.

[6] LEITÃO, M. F. F. Consulta pessoal. Campinas, UNICAMP/FEA, 1999.

[7] PETRUS, R. R.; FARIA, J. A. F. Sistema de embalagem para bebidas isotônicas. Revista Técnica de Bebidas e Alimentos Engarrafador Moderno, São Caetano do Sul, v. 10, n.68, p.40-41, ago., 1999.

[8] QUEST INTERNATIONAL. Osmolarity. Naarden, 1996. $2 \mathrm{p}$.
[9] RUSIG, O. Consulta pessoal. Campinas, 1998.

[10] SOFOS, J. N. Sorbate food preservatives. Boca Raton CRC, 1989. 237p.

[11] SREBERNICH, S. M. Caracterização física e química da água de fruto de coco (cocos nucifera), variedades gigante e híbrido $\mathrm{pb}-121$, visando o desenvolvimento de uma bebida com caracteristicas próximas às da água de coco. Campinas-SP, 1998. 189p. Tese (Doutora em Tecnologia de Alimentos) Faculdade de Engenharia de Alimentos, Universidade Estadual de Campinas (UNICAMP).

[12] STUMBO, C. R. Thermobacteriology in food processing. $2^{-}$ed. London: Academic Press, 1973.329p.

[13] VARNAM, A. H.; SUTHERLAND, J. P. Beverages: technology, chemistry and microbiology. London: Chapman \& Hall, 1994.v.2.

[14] VOIROL, F. Energy drinks, s.n.t. 32p

\section{6 - AGRADECIMENTOS}

À Coordenação de Aperfeiçoamento de Pessoal de Nivel Superior (CAPES) e Fundação de Amparo à Pesquisa do Estado de São Paulo (FAPESP) pelo apoio financeiro concedido. 